\title{
RESEARCH OF THE ACTIVITIES OF THE ENTERPRISES OF THE PERFUME AND COSMETIC INDUSTRY OF UKRAINE
}

\author{
Iryna Kazakova \\ Department of Management, Economics and Quality Assurance in Pharmacy ${ }^{1}$ \\ quality@nuph.edu.ua \\ Viacheslav Lebedynets \\ Department of Management, Economics and Quality Assurance in Pharmacy ${ }^{1}$ \\ quality@nuph.edu.ua \\ Svitlana Kovalenko \\ Department of Management, Economics and Quality Assurance in Pharmacy ${ }^{1}$ \\ Svetlana_kovalenko77@ukr.net \\ Viktoriya Kazakova \\ Department of Cosmetology and Aromology ${ }^{1}$ \\ kazakova10@i.ua \\ ${ }^{1}$ National University of Pharmacy \\ 53 Pushkinska str., Kharkiv, Ukraine, 61002
}

\begin{abstract}
The perfumery and cosmetic industry of Ukraine is distinguished by its dynamic development and makes a significant contribution to the country's economy. Several types of economic activities are involved in its functioning, including the development, research, production and sale of perfumery and cosmetic products, as well as the provision of cosmetic services to the population. The economic activity of each sector in the chain of creation, production and sale of cosmetic products/services determines both their individual success and the efficiency of the entire system as a whole. In this regard, the systematization and analysis of the indicators of economic activity of enterprises of each type of activity of the national cosmetic industry is an urgent task, the solution of which will reasonably determine the prospects for both the further development of this industry and the export potential of the Ukrainian economy as a whole.

The aim of this work was to conduct a comprehensive study of the dynamics of the main indicators of Ukrainian enterprises of perfumery, cosmetic and related industries economic activity for the period 2010-2019 and determination of their development trends. The available data of the State Statistics Service of Ukraine, the Patent Office of Ukraine, as well as a database of scientific and professional publications publications were used as materials and methods. Retrospective, logical, research methods, as well as the method of content analysis were used.

The results of a comparative analysis of the main indicators of the economic activity of business entities in the studied industry made it possible to establish trends in the development of this sector of the economy and substantiate the patterns observed at the present stage.

Conclusions. The results of the study indicate that the production potential of the perfumery and cosmetic industry in Ukraine is promising, as well as significant opportunities for further development of the trade in these products and the provision of cosmetic services to the population.
\end{abstract}

Keywords: perfumery and cosmetic industry, cosmetic products, cosmetic services, wholesale trade, retail trade in perfumery and cosmetic products.

DOI: $10.21303 / 2504-5679.2021 .001700$

\section{Introduction}

The perfumery and cosmetics market is powerful and dynamic, driven by strong growth potential for consumption. In recent years, consumers have been spending higher income on cosmetics than in the previous period [1]. The global sales of cosmetics online, which grew by $27 \%$, are particularly dynamic [2]. The global cosmetic market is one of the most profitable and in 2019 was estimated at 532 billion dollars [3]. 
The maximum growth of the global cosmetics market was recorded at $5.5 \%$ in 2018 . A slight decrease was recorded to $5.25 \%$ in 2019 [4]. The economic and investment attractiveness of the industry determines the practical interest of researchers in all areas of its development. A number of authors pay attention to the analysis of the modern cosmetic market: K. Yu. Aleksandrova, O. N Rudenko [5], E. A. Ignatova [6], considering mainly the structure of the Russian cosmetics market. Nora Amberg [7] in her works focuses on the environmental problems of the industry, Baytsar R. I., Kordiyaka Iu. M. [8] describe the topic of technical regulation of the PCP. Scientists analyze aspects of the quality and safety of the PCP [9-11], the implementation of ISO quality standards into the cosmetic industry $[12,13]$. The authors of the analyzed works study certain aspects of the cosmetic industry - economic, production, environmental and do not consider it as an integral system of inter-industry relations in the life cycle of cosmetic products. There is no methodology for studying the industry as a multifactorial sphere of the country's economy, the patterns and prospects of inter-industry interaction are not considered.

Despite a wide range of studies in the field of the cosmetic industry, they lack a comprehensive study of the problems of the functioning of all life spheres of the PCP/CS. This is especially important for Ukraine, which is currently at the stage of reforming the perfumery and cosmetic industry. The analysis of the industrial enterprises activities is also relevant for the consumer market of Ukraine, where the share of the products of this industry occupies a leading position. Thus, in the structure of retail trade in non-food products in 2019, PCP ranked third in terms of sales $21.7 \%$ (for comparison, pharmaceutical products - $16 \%$ ). Growth in retail turnover for the period 2018-2019 also has one of the maximum values and equals $8 \%$ (for comparison, pharmaceutical products $-5 \%)[14,15]$. These facts indicate a significant potential for the competitiveness of the PCP market and the investment attractiveness of this sector, which is also confirmed by the works of a number of authors $[13,14]$.

The aim of the research. The purpose of our study was to conduct a comprehensive study of the dynamics of the main indicators of economic activity of Ukrainian enterprises of perfumery and cosmetic and related industries for the period 2010-2019 and determination of their development trends.

\section{Materials and methods}

To study the functioning features of such a multilateral sphere of the national economy as the perfumery and cosmetic industry, the task was set to comprehensively investigate all areas of its activity and study the trends of their development. Enterprises, representing all spheres of activity of the cosmetic industry in Ukraine, were selected as objects of research. To establish the patterns of their intersectoral interaction, the main indicators of their economic activity for the period 2010-2019 were studied and promising areas of development were identified.

To achieve this goal, the following research algorithm was applied:

- definition and study of the PCP/CS life cycle system as the result of economic activity of business entities in the relevant sectors of the economy;

- analysis of the domestic classification system of economic activities in the perfumery and cosmetics industry and related sectors of the economy;

- conduction of the comparative analysis of the dynamics of the main indicators of the activities of business entities in the perfumery and cosmetics industry and related sectors of the economy.

The research was carried out using Internet databases: the State Statistics Service of Ukraine, the Patent Office of Ukraine, scientific and professional databases. Retrospective, logical, research methods, method of content analysis were used.

The subject of the retrospective analysis was the economic activity of enterprises in all spheres of activity of the perfumery and cosmetic industry for the period 2010-2019. The logical research method by means of theoretical analysis was used in the format of scientific reproduction of the development dynamics of such a diversified research object as the cosmetic industry. The research method was implemented in the process of studying and conceptualizing the theory of studying the perfumery and cosmetic industry as an economically and socially significant sphere of the 
national economy. The method of content analysis was used for a quantitative analysis of the industry information base with the aim of subsequent meaningful interpretation of the revealed patterns.

\section{Results}

The perfume and cosmetics industry of Ukraine is an important element of the country's economic potential. PCP and CS are socially significant and daily used by the population. In fact, the cosmetics industry should be considered as a multifactorial sphere of economic and social activity, focused on both economic efficiency and the preservation of public health and the formation of the social status of the individual. At the same time, the vector of the perfumery and cosmetic industry development is potentiated by its exceptional dynamism, due to the growth of global urbanization, qualitative changes in the labor market, an increase in the number of elderly citizens, an increase in the standard of living of the population, etc. These features of the evolution of the cosmetic industry around the world determine its innovative appeal, the widespread introduction of scientific achievements in organic chemistry, biotechnology, genetic engineering, materials science and other scientific fields, as well as the growing relationship with related sciences - pharmacy, biology, medicine.

The growth in the science intensity of the cosmetic industry is stimulated by its diversification into the pharmaceutical healthcare sector. Consumer interest in cosmetic products is growing, and, as a result, its share in the «pharmacy basket» among those products that are capable of providing both cosmetic and therapeutic effects on the skin and the human body (and animals) as a whole increases. In Ukraine, a certain segment of such products has the status of «medicinal cosmetics». In the USA, India, Japan, China, a similar category of drugs that combine therapeutic and cosmetic effects on the skin (the so-called special-purpose cosmetics, quasi-cosmetics) is also presented [16]. In the countries of the European Union, such products are defined as «cosmeceuticals» [17]. To date, the promising nature of the combination of cosmetic skin care and its dermatological treatment for various pathological conditions has been proven [18]. The possibility of a dual therapeutic and cosmetic effect, primarily for personal hygiene products, is especially relevant for the global cosmetic industry in the context of a difficult epidemiological situation associated with the COVID-19 pandemic [19]. Also, the development of a related type of pharmaceutical production allows the cosmetic industry to expand the range of products and conquer new sales markets.

To study the special functioning features of such a multilateral sphere of the national economy as the perfumery and cosmetic industry, we set the task of comprehensively investigating of all the areas of its activity and studying the trends of their development. The expediency of a systematic approach in studying the activities of enterprises in the industry is also confirmed by the research of a number of authors [20,21].

In order to establish the main directions of entrepreneurship in the research area, we have identified the main stages of the entire life cycle of PCP and CS as the results of economic activity of business entities. A special feature of the perfumery and cosmetic industry is its active integration into related areas of activity. The processes of interaction with them are presented in the form of a diagram of the main stages of the process of creating «added value» of products/services (Fig. 1).

In general, the perfumery and cosmetic sector is characterized by a high multiplicative effect due to the developed intersectoral relations with various sectors of the economy, the objects of activity of which are also PCP and CS.

The process of creating «added value» of products/services is formed at the stage of marketing research, research and development, and ends at the stage of application/use by a consumer. The stages of the life cycle of products/services directly involve enterprises in the sphere of trade and the provision of cosmetic services, which sell them to a consumer. Taking into account the intended purpose of the products/services, a common object of influence was proposed as a unifying factor for them - a consumer, and more specifically - a human skin and its appendages, as well as the result of their action on the object of influence - the observed cosmetic effect. This approach defines specific requirements for the safety and efficiency of PCP and CS.

A schematic representation of the main stages of the process of creating «added value» of cosmetic products/services is shown in Fig. 1. 


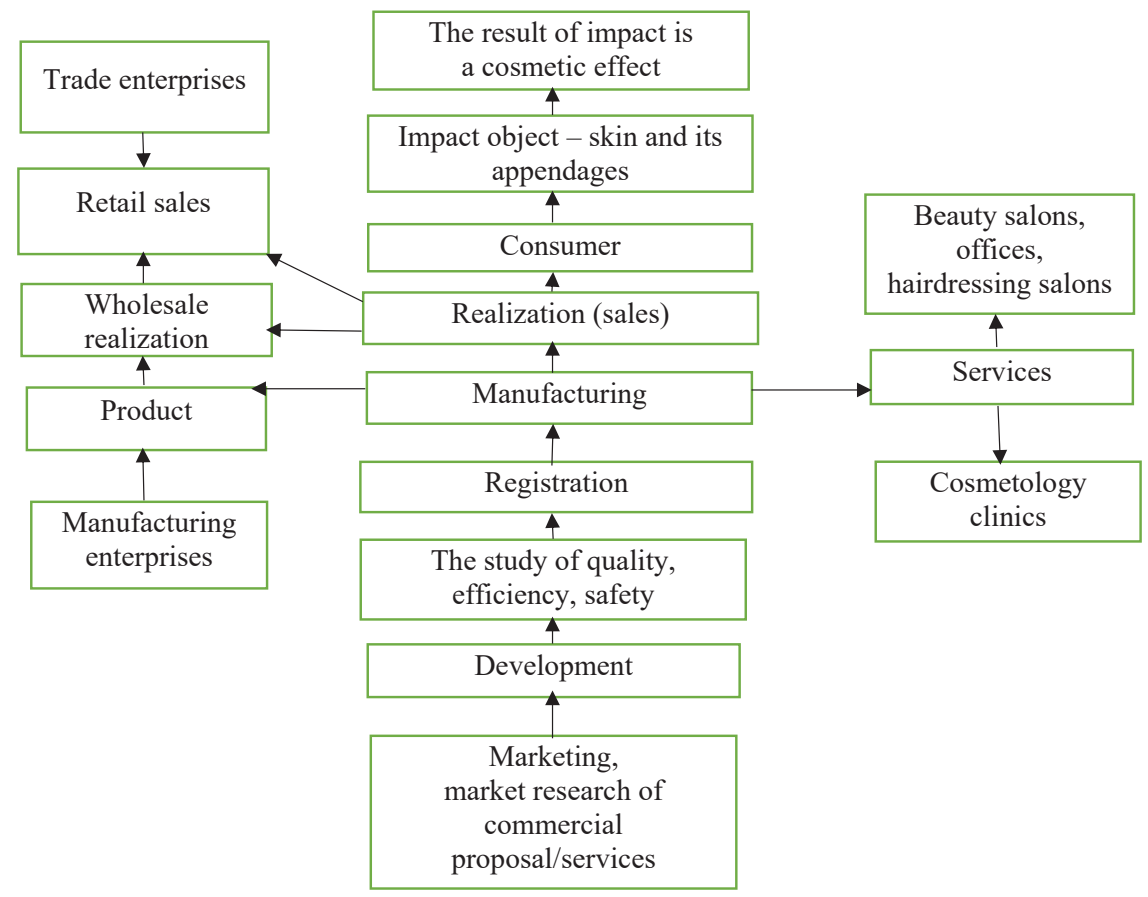

Fig. 1. Outline of the main stages of the process of «added value» of cosmetic products/services creation

As follows from the presented diagram, the chain of processes for creating «added value» of cosmetic products/services is integrated into such types of economic activities as industrial production, trade, as well as the sphere of providing CS. These types of activities are carried out by industrial and commercial enterprises, as well as by enterprises for the provision of CS to the population. CS are the result of the economic activities of enterprises providing them and are represented by beauty salons, clinics, hairdressing salons. CS, unlike PCP, cannot be sold separately from their manufacturing process. Their provision to the consumer coincides with the moment of their production completion. Thus, it is logical to consider the system of life processes of products and services as a single cycle, united as a result of the interaction of a number of related sectors of the national economy.

In order to structure business entities in the field of perfumery and cosmetics industry and further analyze their activities, we have studied the national classification system of economic activities. The requirements for the classification of economic activities in Ukraine are regulated by the classifier of economic activities (CEA SC 009: 2010), which is developed on the basis of the international standard NACE (Classification of economic activities of the European Community; NACE: acronym from the French Nomenclature générale des Activites économiques dans les Communautés Européennes), and approved by the order of the State Committee of Ukraine for Technical Regulation and Consumer Policy No. 457 dated 11.10.2010, entered into force from 1 January 2012 [22]. With regard to the studied areas of activity, we have given their hierarchy in accordance with the structure of the CEA SC 009:2010, which is presented in Table 1.

The types of products and services corresponding to certain types of activity were systematized for the studied classes of CEA SC 009:2010, which is presented in Table 2.

With regard to the systematized subclasses in accordance with the CEA SC 009:2010, the results of business entities work of the cosmetic industry for the period 2010-2019 were studied. For enterprises engaged in the production of PCP, wholesale and retail trade, as well as the provision of CS, the following indicators were analyzed: the number of business entities and employees at enterprises, the volume of production and sales of products/services, the number of profitable/unprofitable enterprises, the level of profitability/unprofitableness of activities. 
Table 1

Systematization of activities in the cosmetic industry according to the classification levels of CEA SC 009:2010

\begin{tabular}{|c|c|c|c|}
\hline Units & Sections & Groups & Classes \\
\hline D. Processing industry & $\begin{array}{l}\text { 20. Manufacture of } \\
\text { chemicals and chemical } \\
\text { products }\end{array}$ & $\begin{array}{l}\text { 20.4. Manufacture of soap and } \\
\text { detergents, cleaning and polishing } \\
\text { products, perfumes and cosmetics }\end{array}$ & $\begin{array}{l}20.42 \text {. Perfumery and cosmetics } \\
\text { production }\end{array}$ \\
\hline $\begin{array}{l}\text { G. Wholesale and retail trade; } \\
\text { repair of motor vehicles and } \\
\text { motorcycles }\end{array}$ & $\begin{array}{l}\text { 46. } 46 . \text { Wholesale trade, } \\
\text { except for motor vehicles } \\
\text { and motorcycles trade }\end{array}$ & 46.4. Wholesale of household goods & $\begin{array}{l}\text { 46.45. Wholesale of perfumery } \\
\text { and cosmetic products }\end{array}$ \\
\hline $\begin{array}{l}\text { G. Wholesale and retail trade; } \\
\text { repair of motor vehicles and } \\
\text { motorcycles }\end{array}$ & $\begin{array}{l}\text { 47. Retail trade, except } \\
\text { for motor vehicles and } \\
\text { motorcycles trade }\end{array}$ & $\begin{array}{l}\text { 47.7. Retail trade of other goods in } \\
\text { specialized stores }\end{array}$ & $\begin{array}{l}\text { 47.75. Retail trade of cosmetics } \\
\text { and toiletries in specialized } \\
\text { stores }\end{array}$ \\
\hline $\begin{array}{l}\text { S. Provision of other types of } \\
\text { services }\end{array}$ & $\begin{array}{l}\text { 96. Provision of other } \\
\text { customized services }\end{array}$ & $\begin{array}{l}\text { 96.0. Provision of other customized } \\
\text { services }\end{array}$ & $\begin{array}{l}\text { 96.02. Provision of services by } \\
\text { hairdressers and beauty salons }\end{array}$ \\
\hline
\end{tabular}

Table 2

Systematization of types of products and services corresponding to certain types of economic activity according to CEA SC 009:2010

\begin{tabular}{|c|c|}
\hline Classes & Subclasses \\
\hline $\begin{array}{l}20.42 \text { Perfumery and cosmetics } \\
\text { production }\end{array}$ & $\begin{array}{l}\text { Production of perfumery and eau de toilette, cosmetics and make-up products, sunscreens and } \\
\text { tanning products, manicure and pedicure products, shampoos, hair sprays, curling and hair } \\
\text { straightening products, toothpastes, powders and oral hygiene products, including fixing agents } \\
\text { for dentures, shaving products, including pre- and post-shave skin care products, deodorants } \\
\text { and bath salts, depilatory products, and the production of cosmetic soaps. }\end{array}$ \\
\hline
\end{tabular}

46.45 Wholesale of perfumery Wholesale of perfumery, cosmetic products and soap.

and cosmetic products

47.75 Retail sale of cosmetics and Retail trade of perfumery, cosmetic and toilet goods toiletries in specialized stores

96.02 Provision of services by hair washing, trimming and cutting, styling, dyeing, toning, curling, hair straightening and hairdressers and beauty salons similar types of services that are provided for men and women; shaving and trimming the beard; face massage, manicure and pedicure, make-up, etc.

Also, the dynamics of a number of indicators was studied depending on the categories of enterprises. The work used statistical information from the State Statistics Service of Ukraine [23].

The dynamics of the number of business entities employed in all sectors of the cosmetic industry is shown in Fig. 2. It indicates a predominant increase in their number during 2010-2019.

As follows from the data mentioned above, the largest number of enterprises is registered in the sector of CS, followed by the retail and wholesale trade. The smallest number of enterprises is registered in the production of PCP. The growth rates of the number of enterprises have positive trends in all types of activities. The maximum growth over the years is typical for enterprises providing CS to the population. For all spheres of activity, the largest number of enterprises and positive dynamics are characteristic to the categories of small enterprises.

The dynamics of the number of employees in the Ukrainian cosmetics industry by sectors was also analyzed (Fig. 3).

It is noted that the dynamics of the number of employees at enterprises of all types of activity demonstrate positive trends. The maximum number of employed and positive dynamics are typical for the sector of CS providing to the population, primarily for the category of small enterprises. The smallest number of employees was recorded for the industrial production sector, in which the largest growth was also noted for small and micro-enterprises. In the trade sector, both 
wholesale and retail, there has been a slight increase in recent years, more pronounced also for small businesses.

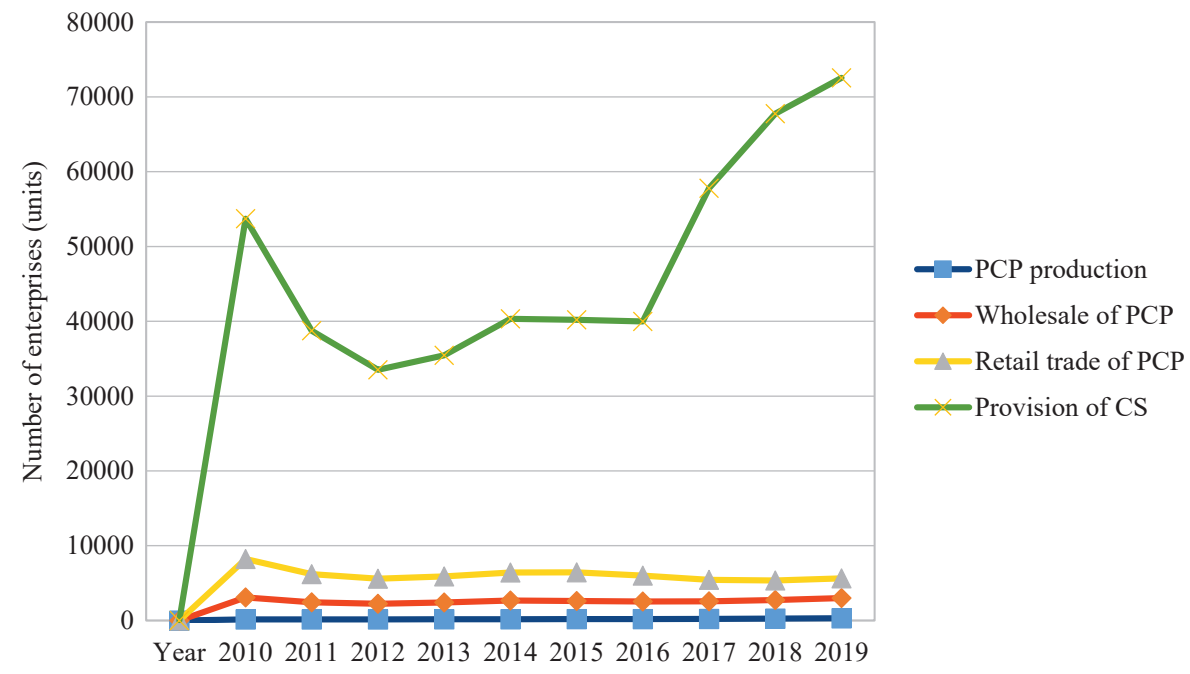

Fig. 2. The number of business entities in the areas of production, wholesale, retail trade of PCP and provision of CS

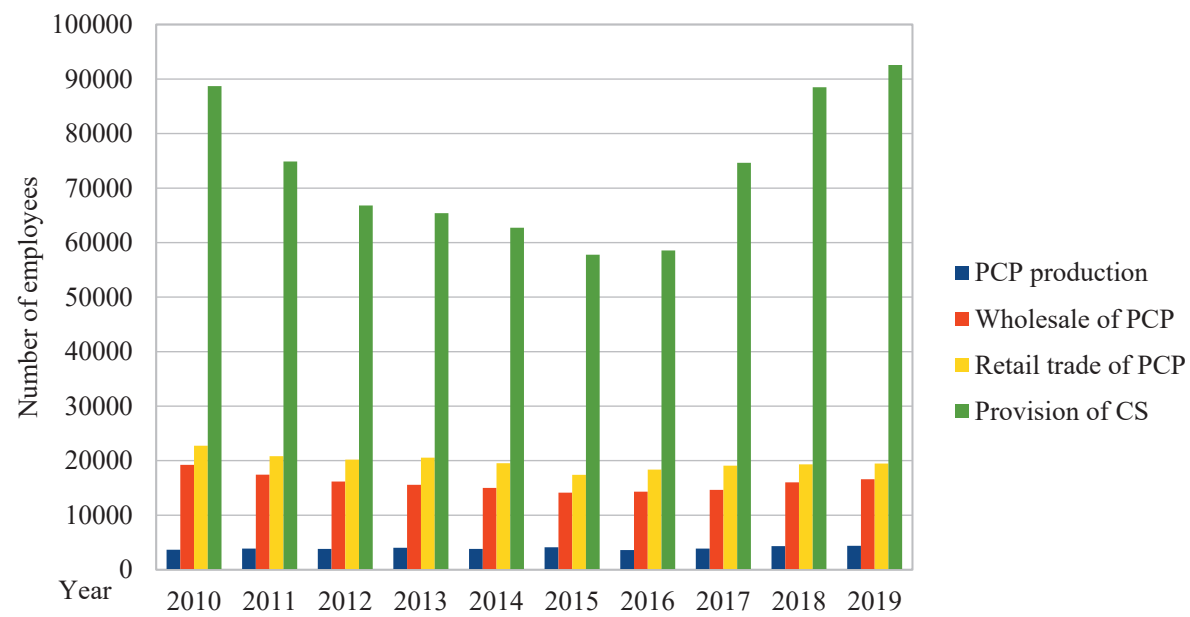

Fig. 3. The number of employees in the areas of production, wholesale, retail trade of PCP and provision CS

The next step of work was the assessment of changes in the volume of production of services/products by the enterprises of the industry for the period 2013-2019 (Fig. 4).

The analysis of the obtained results represents the positive trends of this indicator for enterprises of all types of activity, among which the highest volumes and growth is distinguished by the sector of providing CS. This is primarily due to the activities of small and micro-enterprises. This is followed by the wholesale sector, the success of which, according to this indicator, is determined by medium-sized enterprises. The PCP industrial production sector shows a stable increase in production volumes, mainly due to medium-sized enterprises. Scope of retail sales in 2018 reduced the growth rate of production volumes based on the results of the work of large enterprises.

We also analyzed the volume of products/services sales provided by the enterprises of the industry for the period 2010-2019. The dynamics of this indicator for enterprises of all types of economic activity is shown in Fig. 5. 


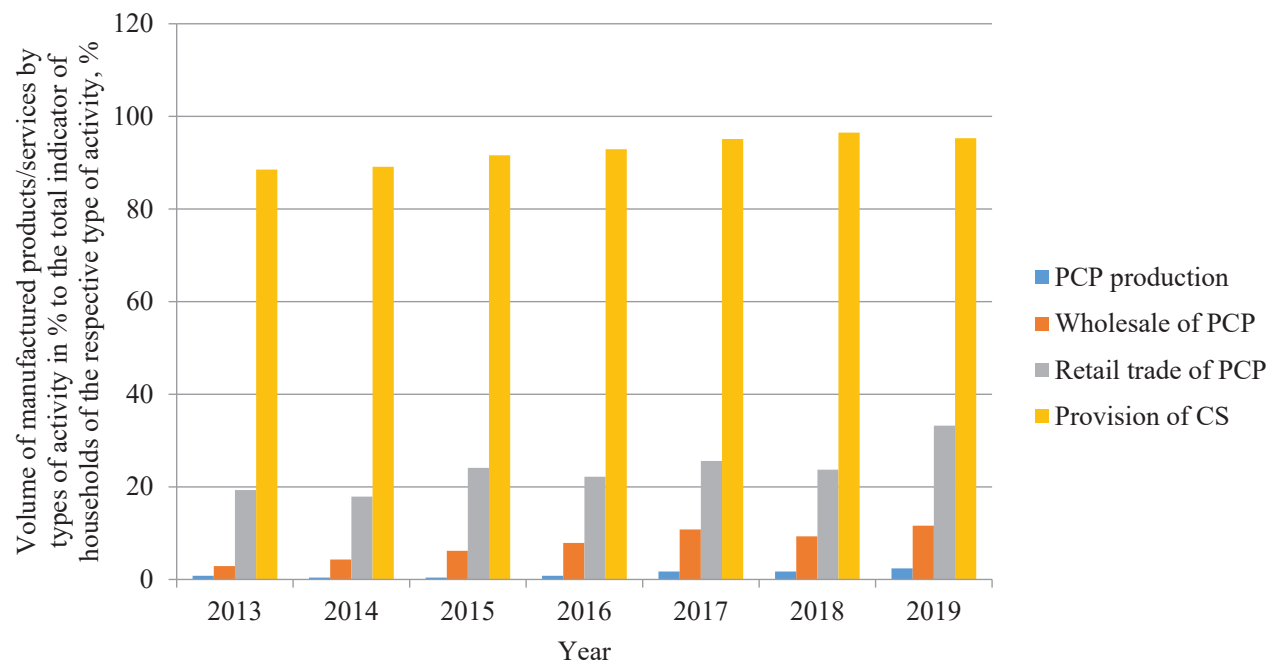

Fig. 4. Volumes of production of goods/services in the areas of production, wholesale, retail trade and provision of CS in \% ratio to the total indicator of economic entities of the corresponding type of activity.

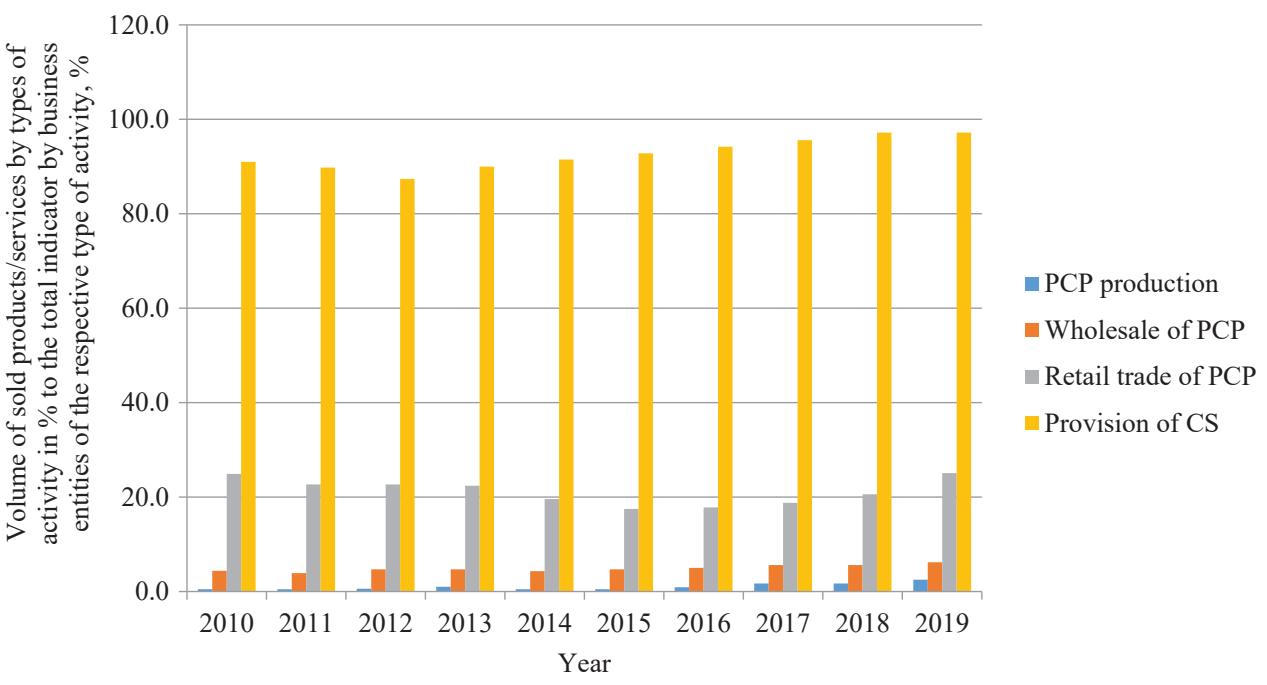

Fig. 5. The volume of sales of products/services in the areas of production, wholesale, retail trade and provision of $\mathrm{CS}$ in $\%$ ratio to the total indicator of economic entities of the corresponding type of activity

In terms of sales volumes, all enterprises also demonstrate positive growth trends. The maximum indicators are typical for the sector of CS providing, followed by the wholesale trade, the success of which is associated with an increase in sales by large and medium-sized enterprises. The sales volumes of beauty salons services, being more than 3 times lower than the wholesale trade, demonstrate the highest growth dynamics of this indicator over the years. This activity is provided by small and micro-enterprises. The retail sector is also increasing its sales volumes, mainly due to small and micro-enterprises. The manufacturing sector demonstrates a stable growth in sales volumes, which is associated with the positive dynamics of PCP sales by medium-sized enterprises.

The indicators of the economic efficiency of enterprises in the studied industries were analyzed at the next stage of the work. Fig. 6 shows the results of the ratio of profitable business entities as a percentage of the total number of enterprises of all types of economic activity. Data analysis is provided on the basis of statistical information of the State Statistics Service of Ukraine [23]. 


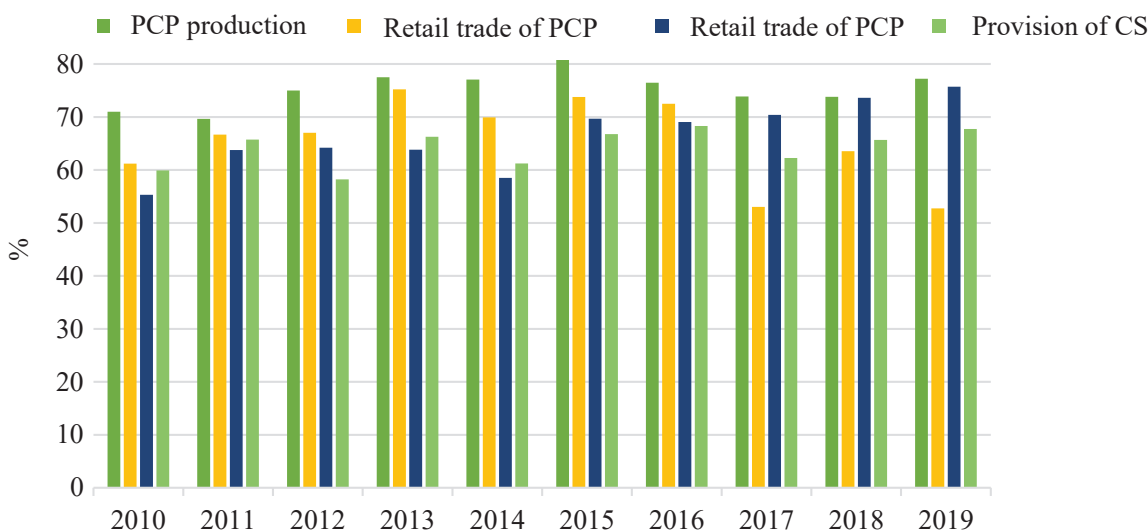

Fig. 6. The percentage of profitable enterprises in the areas of production, wholesale, retail trade of $\mathrm{PCP}$ and provision of $\mathrm{CS}$ of their total number

As follows from the presented data, the manufacturing sector demonstrates the highest indicator of the number of profitable enterprises. At the same time, the dynamics of the indicator is negative, starting from 2016. In 2019, the number of profitable businesses is increasing due to the activities of small businesses.

The wholesale sector has shown positive growth trends in the number of profitable businesses since 2017 thanks to the activities of large and medium-sized enterprises. The dynamics of the number of profitable retail enterprises in the study period is unstable, which is more influenced by enterprises of medium and small categories. Profitable CS enterprises also demonstrate instability, which is determined by the activities of medium-sized enterprises.

The economic efficiency of enterprises in all industries was evaluated as based on the results of the profitability level of their activities, the indicators of which in the dynamics of 2010-2019 are shown in Fig. 7.

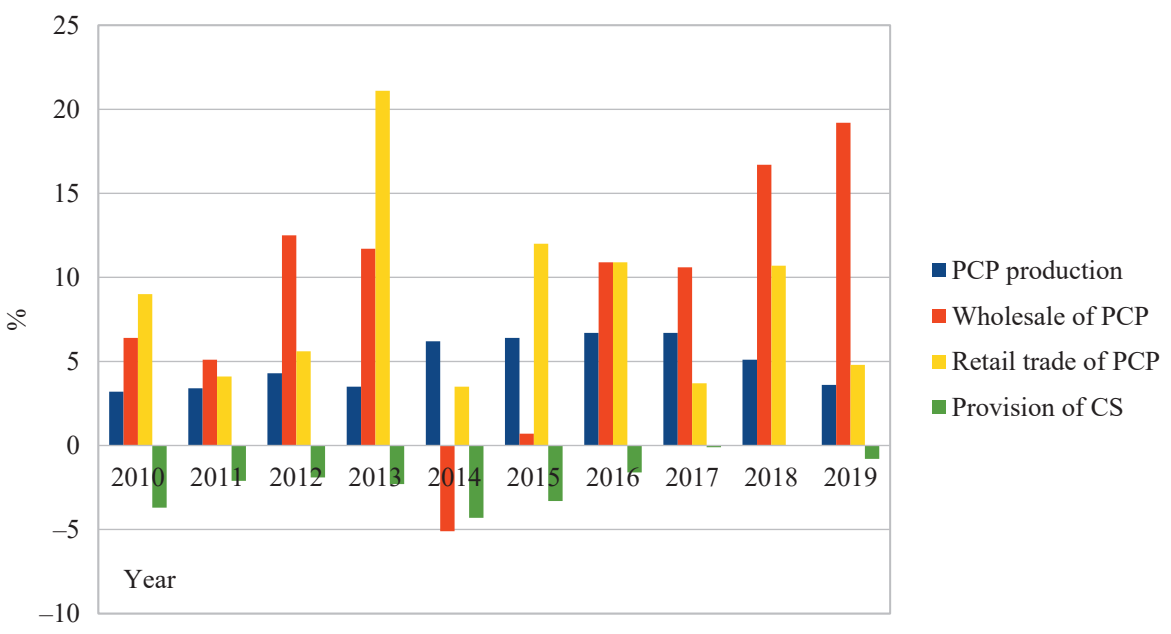

Fig. 7. The level of profitability of enterprises in the spheres of production, wholesale, retail trade of PCP and provision of CS

As follows from the data mentioned above, higher results of economic efficiency in recent years are characteristic of wholesale enterprises, primarily due to the success of medium and small enterprises. The retail sector is characterized by unstable dynamics of economic efficiency of enterprises. The economic result is provided mainly by large enterprises, medium and small enterprises are systemically unprofitable. In recent years, the production sector has been reducing the level of profitability due to a decrease in the efficiency of medium-sized enterprises. 
The activities of enterprises for the provision of CS are characterized by economic inefficiency. They systematically demonstrate unprofitableness, excluding the activities of microenterprises, for the entire study period.

\section{Discussion of research results}

It is possible to determine the general trends in the development of the industry as a whole by analyzing the results of the activities of enterprises over a 10-year period. As follows from the data provided, the production and sale of perfumery and cosmetic products and cosmetic services are promising areas of the national economy of Ukraine. This confirms the conclusions of the scientific works of R. I. Baytsar, Iu. M. Kordiyaka, Ya. V. Kononenko on the relevance of the perfumery and cosmetic industry for the country's economy $[8,9]$. The expediency of a comprehensive consideration of the perfumery and cosmetic industry is confirmed by the findings of Nora Amberg [7], in whose works the main attention is paid to the environmental aspects of industrial enterprises. Natasha Ketabchi [20], studying the development trends of the cosmetic market at the present stage, also takes into account the multifactor effect of the development of the perfumery and cosmetic industry.

The results of our work allow us to draw conclusions about the prospects for all related areas of activity of enterprises engaged in the production and implementation of $\mathrm{PCP} / \mathrm{CS}$. The studied types of economic activities are represented by more than 76 thousand business entities, which employ more than 130 thousand workers. The largest number of enterprises is concentrated in the sector of providing cosmetic services and reaches more than 70 thousand units, followed by the number of economic entities is the sector of retail sales which equals 5358 enterprises. The wholesale sector is provided with 3 thousand enterprises, the production sector is represented by 307 enterprises. The category of large enterprises is not represented in the production of perfumery and cosmetic products; medium-sized enterprises prevail. The trade sector is represented by all categories of enterprises, while the wholesale trade is dominated by small businesses. The retail sector is dominated by medium and small businesses, mostly at the expense of microenterprises. There are no large enterprises in the field of providing cosmetic services; the majority of business entities are represented by the category of small enterprises. The significant role of small business indicates a developed competitive environment and a high level of entrepreneurial activity, which is a potential for economic growth of the studied types of activity. With regard to the number of employees in each type of economic activity, it should be noted that the majority of employees are in the provision of cosmetic services - about 93 thousand, in retail sales - about 20 thousand, in the field of wholesale - about 17 thousand and in the manufacturing sector - more than 4 thousand people. The number of business entities and employed workers in all types of economic activity has a positive growth trend. These facts testify to the significant labor resources of the industries, which is the potential for further growth of their business activity.

Assessing the effectiveness of the economic activity of enterprises in general, it should be noted the growth of economic activity of enterprises in the research period. Stably positive dynamics of production volumes and sales of products / services is typical for all types of economic activity.

The results of economic efficiency indicate the significant potential of the industrial sector, the percentage of profitable enterprises of which is the highest. Its level in 2019 was $4 \%$ higher than the average Ukrainian indicator. The effectiveness of the economic efficiency of this sector is determined mainly by the results of the work of medium-sized enterprises, whose indicators exceed the level of profitability of small industries by almost 3 times. At the same time, the decrease in the profitability of medium-sized enterprises in 2018 by almost $2 \%$ compared to 2016 may indicate incorrectly chosen development directions or insufficiently effective organization of work in this sector in a highly competitive environment.

The economic efficiency of small enterprises has positive growth trends in 2017. It increased by $1.6 \%$. A decrease in the indicator by $0.8 \%$ in 2018 , which is associated with the unstable performance of microenterprises, the economic efficiency of which, starting from 2014, has an unstable jump character.

Thus, it can be stated that the industrial sector is distinguished by a significant resource base and production potential, which is provided by medium-sized enterprises. Small enterprises 
show significantly lower economic efficiency. The unstable economic activity of microenterprises is among the reasons for it. At the same time, there are prospects for increasing economic activity for small enterprises due to the generally positive dynamics of the profitability level.

In recent years, the wholesale trade sector has shown an increase in the number of business entities, mainly due to an increase in the number of small businesses. The retail network is characterized by unstable dynamics of the number of business entities due to similar trends on the part of small businesses. It should also be noted that the number of people employed in the trade sector has increased, which indicates its resource potential. The performance of the economic activity of the trading sector during the study period is characterized by instability. The level of profitability of wholesale enterprises of all categories, after a sharp drop in 2014, has increased in recent years and exceeded the same indicator in the manufacturing sector by more than 3 times. The economic success of enterprises in the sector by categories is characterized by high indicators for large and small enterprises at the end of 2018, among which micro-enterprises also showed significant growth against the background of low efficiency over the entire previous period.

The retail sector is less economically successful. The indicators of services and sales economic efficiency with an increase in their volume are unstable. They are, in general, 1.5 times less than in the wholesale sector. Evaluating the activities of individual categories, we note an increase in the level of profitability only for large enterprises; business entities of the middle category are systemically unprofitable. In general, trade enterprises are characterized by unstable dynamics of economic success, the results of which are higher for enterprises of all categories of the wholesale sector. Retail trade enterprises are distinguished by lower economic efficiency due to the systemic loss ratio of medium-sized economic entities.

The sector of cosmetology services has the greatest resource potential among the studied types of economic activity. It is represented by the largest number of enterprises, the number of employees and the dynamics of these indicators over the years. At the same time, there is a decrease in the volume of production and sale of services provided for the enterprises of the industry. During the study period, enterprises in the sector are systemically unprofitable and only in 2018 reached the break-even level. Given the confidentiality of data on medium and small enterprises, starting from 2014, we note an increase in the level of profitability for micro-enterprises in 2017 and an improvement in positive dynamics in 2018. Given the sufficiently high potential of the industry's resource base, in general, their activities cannot be considered successful. Micro-enterprises have positive prospects for economic development, which have shown an increase in the level of profitability in recent years.

Taking into account the information mentioned above, it should be noted that the industrial sector is promising, which is characterized by a systematic increase in resource capabilities and economic efficiency. Medium-sized enterprises show themselves confidently in the market, and in recent years there have been noticed positive trends in the activities of small enterprises. The trade sector of the industry is unstable both in terms of the dynamics of the number of enterprises and their employment, and in terms of the performance indicators of enterprises. Great performance is a specific feature of the wholesale link, the result of which determines the activities of large enterprises. The retail sector is less efficient, largely due to the unprofitable activities of medium-sized enterprises. The profitability of large and small enterprises is spasmodic; microenterprises are ineffective.

The sector of cosmetology services is represented by the largest number of enterprises and those working for them, the dynamics of indicators of which is also oriented to increase over the years. At the same time, the indicators of economic activity of enterprises in the sector for 9 years of observation are negative.

Summarizing the information written above, we can note the presence of the following patterns:

- activity and prospects for further successful development of the industrial sector; primarily of medium-sized enterprises;

- unstable economic activity of trade enterprises, among which the most successful are large wholesalers;

- unprofitable sector for the provision of cosmetic services, which, nevertheless, has potential resources to increase economic indicators. 
Study limitations. Research limitations were represented by the confidentiality of economic activities data of certain categories of enterprises in the field of wholesale trade and the provision of cosmetic services.

Prospects for further research. A promising area of further research is the study of the problems of introducing ISO quality standards into the economic activities of enterprises in the production sector of the Ukrainian perfumery and cosmetic industry.

\section{Conclusions}

The process of creating «added value» of cosmetic products/services as the results of economic activity of business entities in related sectors of the economy has been determined and studied.

The outline of the main stages of the process of «added value» of cosmetic products/services creation was presented. While drafting the outline the multiplier effect of the perfumery and cosmetic industry activity was taken into account.

The recommendation to consider the perfumery and cosmetic industry as a complex sphere of the national economy, in the process of intersectoral interaction with which trade enterprises and the provision of cosmetic services are involved, which also form the value creation of products, is substantiated.

The domestic system of classification of types of economic activities in perfumery and cosmetics and related sectors of the economy was studied; systematization of activities, products and services was carried out in accordance with the requirements of CEA SC 009:2010.

A comparative analysis of the dynamics of the main indicators of business entities activities in the perfumery and cosmetic industry, in particular, in the field of trade and the provision of cosmetic services, is carried out.

An assessment of the volume and dynamics of production and human resources, indicators of economic efficiency of each type of activity of the studied industries was made. This assessment made it possible to determine the potential of its capabilities and the prospects for their implementation, among which is the increase in production and economic resources by the industrial sector, in which medium-sized enterprises have preferential prospects.

The statement is substantiated that the recovery of economic activity of enterprises in the trade sector is possible, first of all, at the expense of large enterprises of the wholesale link.

It is shown that the rational use of the resource base by the sector for the provision of cosmetic services to the population, as well as the improvement of the norms and requirements of state control of the economic activities of entities in this industry can bring tangible positive results in the coming years.

\section{Conflicts of interest}

The authors declare that they have no conflicts of interest.

\section{References}

[1] The Beauty 2020-2030 Forecast (2000). Available at: https://www.gcimagazine.com/business/marketing/The-Beauty-20202030-Forecast-569283581.html Last accessed: 01.09.2020

[2] The world of beauty in 2019. Available at: https://www.loreal-finance.com/en/annual-report-2019/cosmetics-market-2-1-0/ Last accessed: 01.09.2020

[3] Jacimovic, D. (2020). 32 Fascinating Beauty Industry Statistics. Available at: https://dealsonhealth.net/beauty-industry-statistics/ Last accessed: 01.09.2020

[4] Annual growth of the global cosmetics market from 2004 to 2019. Available at: https://www.statista.com/statistics/297070/ growth-rate-of-the-global-cosmetics-market/ Last accessed: 01.09.2020

[5] Aleksandrova, K. Iu., Rudenko, O. N. (2016). Financial strategy of perfume and cosmetics industry. Sovremennye nauchnye issledovaniia i innovatsii, 2. Available at: http://web.snauka.ru/issues/2016/02/62897

[6] Ignatova, E. A. (2019). Nekotorye aspekty parfiumerno-kosmeticheskogo rynka i polozhenie L'ORÉAL na nem. Ekonomika i biznes: teoriia i praktika. Available at: https://cyberleninka.ru/article/n/nekotorye-aspekty-parfyumerno-kosmeticheskogo-rynka-i-polozhenie-1-or-al-na-nem/viewer 
[7] Amberg, N. (2018). Environmentally conscious consumer behaviour in the cosmetics markets of the United States and Europe. Available at: https://www.researchgate.net/publication/338233673_ENVIRONMENTALLY_CONSCIOUS_CONSUMER_ BEHAVIOUR_IN_THE_COSMETICS_MARKETS_OF_THE_UNITED_STATES_AND_EUROPE_in_ESZTERHAZY_ KAROLY_EGYETEM_GYONGYOSI_KAROLY_ROBERT_CAMPUS_ESZTERHAZY_KAROLY_UNIVERSITY_A_ TUDOMAN

[8] Baitsar, R. I., Kordiiaka, Yu. M. (2015). Aktualni problemy ta perspektyvy rozvytku kosmetychnoi haluzi. Lviv, 6.

[9] Kononenko, Y. V. (2020). Experience of providing quality standards in investment projects under uncertainty. Economic Bulletin of the National Mining University, 70, 158-167. doi: http://doi.org/10.33271/ev/70.158

[10] Kovalova, O. M., Tsyhulova, O. M., Shumilo, O. M., Dieieva, O. O. (2016). Bezpeka kosmetychnykh tovariv v Ukraini. Medyko-pravovi aspekty ta suchasna koniunktura na vnutrishnomu rynku. Kyiv: FOP «Klymenko», 447.

[11] Galdorfini, B., de Almeida, M. G. J., Antonio, M., Borges Isaac, V. L. (2012). Cosmetics' Quality Control. Latest Research into Quality Control. doi: http://doi.org/10.5772/51846

[12] Implementing ISO Quality Standards in Cosmetics Industry: Incentives and Factors. Available at: https://www.academia. edu/31787688/Implementing_ISO_Quality_Standards_in_Cosmetics_Industry_Incentives_and_Factors

[13] Kazakova, I., Lebedynets, V. (2020). Analysis of the technical regulation state of cosmetic products turnover in Ukraine. ScienceRise, 2, 39-46. doi: http://doi.org/10.21303/2313-8416.2020.001279

[14] Ukraina u tsyfrakh 2019 (2020). Derzhavna sluzhba statystyky Ukrainy. Kyiv. Available at: http://www.ukrstat.gov.ua/druk/ publicat/kat_u/2020/zb/07/zb_Ukraine \%20in \%20figures_u.pdf

[15] Ukraina u tsyfrakh 2018 (2019). Derzhavna sluzhba statystyky Ukrainy. Kyiv. Available at: http://www.ukrstat.gov.ua/druk/ publicat/kat_u/2019/zb/07/Ukr_cifra_2018_u.pdf

[16] Kazakova, I. S., Lebedynets, V. O., Kazakova, V. S. (2020). Issues of standardization of medicinal cosmetics in Ukraine. News of Pharmacy, 2 (100), 84-94. doi: http://doi.org/10.24959/nphj.20.39

[17] Pandey, A., Jatana, G. K., Sonthalia, S. (2020). Cosmeceuticals. Available at: https://www.ncbi.nlm.nih.gov/books/NBK544223/ Last accessed: 01.09.2020

[18] Kresken, J., Kindl, U., Wigger-Alberti, W., Clanner-Engelshofen, B. M., Reinholz, M. (2018). Dermocosmetics for Use in Rosacea: Guideline of the Society for Dermopharmacy. Skin Pharmacology and Physiology, 31 (3), 147-154. doi: http:// doi.org/10.1159/000486688

[19] Cosmeceuticals Market to Reach USD 73.73 Billion by 2026; Covid-19 Pandemic Will Benefit Large Scale Enterprises, says Fortune Business Insights (2020). Available at: https:/www.globenewswire.com/news-release/2020/05/27/2039534/0/en/ Cosmeceuticals-Market-to-Reach-USD-73-73-Billion-by-2026-Covid-19-Pandemic-Will-Benefit-Large-Scale-Enterprisessays-Fortune-Business-Insights.html

[20] Ketabchi, N. Looks That Thrill - Inside the Booming Beauty Industry. Available at: https:/www.toptal.com/finance/ growth-strategy/beauty-industry

[21] Ihnashkina, T., Dushyna, L., Moskalets, T. (2020). World market of perfume-cosmetic products: modern trends and prospects. Market Infrastructure, 41. doi: http://doi.org/10.32843/infrastruct41-14

[22] Klassifikator vidov ekonomicheskoi deiatelnosti (2010). Prikaz Gospotrebstandarta Ukrainy No. 457. 11.10.2010. Available at: https://www.profiwins.com.ua/ru/directories1/economic-activities.html

[23] Gosudarstvennaia sluzhba statistiki Ukrainy. Available at: http://www.ukrstat.gov.ua

This is an open access article under the CC BY license (http://creativecommons.org/licenses/by/4.0).

How to cite: Kazakova, I., Lebedynets, V., Kazakova, V., Kovalenko, S. (2021). Research of the activities of the enterprises of the perfume and cosmetic industry of Ukraine. EUREKA: Health Sciences, 2, 44-55. doi: http://doi.org/10.21303/2504-5679. 2021.001700 